Aleksandra V. Jovanović Univerzitet u Beogradu
УДК

821.133.1.09 Дубровски С.

ДОИ

https://doi.org/10.18485/analiff.2016.28.2.2

\title{
PISANJE O SEBI, PISANJE SEBE
}

\author{
U nekom trenutku u životu (...) \\ čovek mora uvesti red u svoju prošlost ... \\ Vladimir Nabokov, Govori, Sećanje
}

\begin{abstract}
Kada je 1977. Serž Dubrovski definisao žanr autofikcije, istovremeno je pokrenuo teorijsku raspravu o njegovim mogućnostima i granicama. Jedno od osnovnih pitanja je razgraničenje žanra autofikcije u odnosu na tradicionalnu autobiografiju. Zbirka eseja Writing the Self (Pisanje sebe) donosi trideset eseja u kojima se ispituju granice, mogućnosti i tumačenja autofikcije u okviru šireg konteksta poetike postmodernizma. Pitanja kao što su ontološki status teksta i autora personalnog narativa, autentičnost bića i svesti koja piše tekst i kulturološka, politička i istorijska obojenost personalnog diskursa predstavljaju neke od preokupacija autora ovih eseja. Cilj ovog teksta je da predstavi istraživanja koja su opisana u esejima kao i da ukaže na glavne teme rasprave o personalnom tekstu.
\end{abstract}

Ključne reči: autobiografija, autofikcija, autor, personalni tekst, autentičnost, istorija, ideologija, kultura, pisanje.

Rasprava o ontološkom statusu teksta, da li je u pitanju dokument ili fikcija, predstavlja jedno od osnovnih pitanja njegovog tumačenja. Kada je u pitanju pisanje o životu referencijalnost kao da se ne dovodi u pitanje, a sa njom i obaveza pisca (i pripovedača) da crpe iz sopstvenog iskustva. Da li je to uvek tako? Da li je pisanje o sopstvenom životu, autobiografija, sinonim za sećanje? I da li se autor uvek oslanja na pojedinačno, individualno iskustvo? Koliko je pojedninačno iskustvo deo šireg društvenog $\mathrm{i}$ istorijskog konteksta autora $\mathrm{i}$ da li u personalnom tekstu individualna svest može biti „proširena“ tako da zahvati prostor opšteg, opšteljudskog

\footnotetext{
* Filološki fakultet, Univerziteta u Beogradu, Studentski trg 3, e-mail: ningi@sbb.rs 1 Sve citate u tekstu preveo je autor.
} 
ili tuđeg iskustva? Postoje mišljenja da je „obaveza“ autofiktivnog narativa da obuhvati istine drugih, grupe, odnosno da predstavi tuđe iskustvo (Gilmor, 2001: 5, cit. u Shands, 2015: 9). Sledeći Gilmorovu misao, mogli bismo reći da autofiktivni tekst stvara prostor za izmirenje tenzija između pojedinačnog i opšteg. Interesantan je primer koji pokreće autofiktivno delo Rigoberte Menču (Rigoberta Menchu), aktivistkinje iz Gvatamale, dobitnica Nobelove nagrade za mir 1992. Njeno delo, I, Rigoberta Menchu: An Indian Woman in Guatemala (Ja, Rigoberta Menču: Indijanka iz Gvatamale). Menčuovoj su prigovarali da je u svoju autobiografiju uključila događaje koji se nisu njoj dogodili. Rasprava o knjizi Menčuove dobila je oblik rasprave o prirodi reprezentacije iskustva $\mathrm{i}$ autoriteta umetničkog dela. Posebno ako imamo u vidu da se slika o biću temelji na pogledu drugog, na učešću u zajednici, i kolektivnom iskustvu stvarnosti, kulture i jezika.

Od kad je pre gotovo četiri decenije, 1977. godine francuski pisac Serž Dubrovski ustanovio termin ,autofikcija“ kritički dijalog o teorijskim pretpostavkama žanra personalnog teksta neprestano traje. Ova rasprava je tokom vremena obuhvatila razne kritičke fokuse iz domena poetičkih, stilskih i žanrovskih studija. Najčešća tema u teoriji autofikcije ostaje debata o referencijalnosti između iskustva i pripovedanja. Odmah zatim postavlja se pitanje odnosa između autora personalnog teksta i protagoniste priče $u$ kontekstu šire teorijske raprave koju je uvela poststrukturalistička teorija sa kraja dvadesetog veka o mogućnostima i ograničenjima reprezentacije, mnogostrukosti identiteta i konstruisanja subjekta u umetničkom delu.

Jedna od najčešćih debata tiče se pitanja odnosa između subjekta autofiktivnog dela i „ekstratekstualnog modela“ (Shands, 2015: 2). Subjekat autofikcije stvara fiktivni portret koristeći narativne strategije, temporalne i druge zakonitosti kazivanja i oblikovanja, poigravajući se iluzijom istine i verodostojnosti u umetnosti. Autofiktivni tekst crpe opsenarske izmene planova i ravni percepcije koju stvara nestalnost odnosa između, "mene kao autora, mene kao subjekta i mene kao portret koji slika književni tekst" (Hindmarsh, 2005: 5 cit. u Shands, 2015: 7).

Za razliku od klasične autobiografije čiji tekst je fokalizovan u liku njenog subjekta, dela autofikcije ispoljavaju fragmentarnost vizije, nestabilnost tačke gledišta, vremena i percepcije stvarnosti. Smit i Vot- 
son (Sidonie Smith and Julia Watson) podsećaju na četiri aspekta slike subjekta autofikcije, istorijsko 'ja' koje postoji u svakodnevnoj stvarnosti, ‘ja' koje pripoveda i 'ja' koje izranja iz pripovedanja, i najzad, ideološko 'ja'. Na taj način, ističu Smit i Votson naizgled jedinstveno biće postaje u tekstu autofikcije izvor i objekat preispitivanja, prisećanja i kontemplacije (Smith and Watson 59 cit. u Shands, 2015: 11). Kakav je, dakle, odnos između uloga koje nužno fragmentirano biće uzima, "ja kao autor, ja kao subjekat i ja kao fikcionalizovana figura" (8)? Fragmentirni prikaz lika autora najavljuje složenu mrežu odnosa između pisca teksta i protagoniste personalnog narativa.

Smisao zbirke tekstova Writing the Self: Essays on Autobiography and Autofiction (Pisanje sebe: eseji o autobiografiji i autofikciji) je da ukaže na razne vizure iz kojih se može posmatrati lični tekst. Pretpostavka autora eseja je da autobiografski prostor postaje u autofiktivnom istraživanju poprište borbe društvenih glasova. U njima su analizirani načini na koje personalni tekstovi sagledavaju životna iskustva: kroz potragu, samoispitivanje, samopotvdu, i reakcije na marginalizaciju, nevidljivost i zanemarnenost u kolonijalnom, kulturnom, istorijskom i rodnom kontekstu.

Najveći broj eseja bavi se pisanjem života kao identitetskog traganja. U prvom eseju "When I think about myself"”: Identity Building in Maya Angelou's Autobiographical Sequel” (Kada razmišljam o sebi: izgradnja identiteta u autobiografskom ciklusu Maje Angelu). Elis Godfri (Alice Godfrey) analizira delo Maje Angelou, u kontekstu usmene tradicije afroameričkog pripovedanja u devetneastom i dvadesetom veku. Metafora putovanja predstavlja snažno narativno oruđe u tekstu Maje Angelou u kome fizičko putovanje, promena mesta i perspektive ima duboko duhovno značenje. Cilj Godfrejeve je da pokaže kako je proces stvaranja autobiografije doprineo oblikovanju identiteta kod afroameričkih žena (29).

U eseju "The 'Absent Presence' and the Art of Autobiography: Barack Obama's Dreams from My Father ('Odsutno prisustvo' i umetnost autobiografije: Snovi moga oca Baraka Obame), Aparaita Nanda (Aparajita Nanda), opisuje Obamino delo kao fiktivno mitsko putovanje kroz unutrašnje prostore uma u potrazi za "samootkrivanjem". Tekst je smešten u kontekst arhetipske drame koja potiče od ambivalentne veze oca i sina. Paradoksalno to samootkrivanje vodi kroz fiktivno popunjavanje praznine koju je stvorilo odsustvo oca. Slika odnosa sina i oca izranja 
iz predstavljanja dokumentacije o životu fotografija, epizoda iz života i snova. Pričao rekonstrukciji, stvaranju mitskog oca kroz priče i maštu, kao ključ za izgradnju sopstvenog identiteta. Izgradnja figure oca, predstavlja maštanje o mitskoj "Africi” (Smithers 494, cit u Shands 40) kao dalekom, ali čvrstom korenu identiteta.

Elizabet Buzonviler (Elisabeth Bouzonviller) analizira pisanje autobiografije američke književnice Luiz Erdrih (Louise Erdrich) koja svoj život posmatra kroz iskustvo materinstva i arhetipske teme rođenja i odrastanja i života u porodici u tekstu "Maternity and Writing" (Materinstvo i pisanje) Erdrihova ispituje način na koji se u tekstu kroz proces pisanja mogu istraživati najintimnija iskustva života na preseku sa naracijama o univerzalnom ženskom nasleđu (147).

U eseju, "'My Mother Composed Me as I Now Compose Her' (Majka me je stvorila kao što ja sad stvaram nju) Eva-Sabina Zahelin (EvaSabine Zahelein) analizira identitetsku potragu kroz pripovedanje arhetipskog odnosa između majke i ćerke. Tenzija i trauma koje obeležavaju ovaj odnos preslikavaju se u autobiografskom narativu književnice Elison Bekdel (Alison Bechdel) između majke i ćerke obeležavajući sve naracije o njihovim bićima i identitetima. Bekdelova o kojoj piše Zahelinova u tekstu crta "intimni dvostruki portret sebe i svoje majke" (163) da bi "premostivši jaz pronašla i prihvatila sebe" (163).

Džo Vudivis (Jo Woodiwiss) piše o autofikciji iz perspektive teksta "koji pruža pomoć autoru", razjašnjava nas i naše priče (183). Vudivis stavlja autofikciju u širi kontekst tekstova koji nude samoanalizu i potrage za odgovorom na pitanje, Šta nije u redu sa mnom ("What's wrong with me?" u procesu reinterpretacije i oporavka autofikcija nam pomaže da pišemo, odnosno stvaramo sopstveno biće (183). Tendencija modernog društva da nametne sliku o sebi, limitira naše iskustvo života jer pokušavamo da se "uklopimo u postojeće priče" (182). Autobiografski narativ predstavlja priliku stvaranja prostora za istinsko samoistraživanje (184).

Kirsi Tuohela (Kirsi Tuohela) ispituje autobiografije mentalno obolelih bolesnika, odnosno pisaca-amatera. Tuohela piše o finskim piscima amaterima koji su opisali svoj slučaj odbacivanja ispravnog religijskog puta što ih je odvelo u ludilo. Tohela piše kako su od prosvetiteljstva naovamo individualne priče postajale sve više tema književnosti, a pisanje o mentalnim bolestima posebno bilo popularno u drugoj polovini devetnaes- 
tog veka. Postojalo je izuzetno interesovanje za saznavanje o iskustvima o vraćanju na pravi put, kao i ličnim ispovestima o doživljaju nervnog rastrojstva u ovim autobiografijama opisana su iskustva napuštanja boga, povratka i oporavka, života u "paklu" i povratka (220).

Lamia Mokrejn (Lamia Mokrane) bavi se pitanjem da li je moguće pisati autobiografiju nekoga drugog. Govoreći o delu Autobiografija moje majke Džamajke Kinseid (Jamaica Kincaid) Mokrejnova skreće pažnju najpre na paradoks koji je sadržan u naslovu. Identitet glavne junakinje izranja iz priče, autobiografije o životu u majčinom odsustvu, činji intenzitet, ispunjenje osećanjem gubitka i uzaludnosti gradi identitet autorke kao i figure majke u tekstu (232).

Majkl Aklend (Michael Ackland) u eseju o "Unchained Eve" (Oslobođena Eva) piše o preispitivanju sopstvene autobiografije sa stanovišta raznih ideologija. Aklend analizira autobiografiju Kristine Sted (Christine Stead) u kojoj feministička i marksistička filozofija "uzurpiraju mesto božanstva u ulozi pokretača društvenog i individualnog razvoja" (299). Naime, Stedova piše o svom duhovnom razvitku pronalazeći paralele između marksizma i hrišćanstva, ali deleći marksistički prezir prema religiji i oslanjajući se na individualnost i konceptualizujući biblijsko učenje u skladu sa feminističkim stavovima. Fiktivni zapleti i događaji stvoreni su na osnovu stvarnih ličnosti iz života. Stedova naseljava biblijski pejzaž ličnostima iz sopstvenog života. Na primer, njen otac David, prikazan je kao Adam, a njena zemlja, Australija kao "plodna, nevina bašta" (299).

Teme identiteta, marginalizacije i borbe za vidljivost i samopotvrdu u okviru autofiktivnog teksta prožimaju nekoliko eseja. Dipti Patanaik (Dipti R. Pattanaik) piše o tome na koji način autobiografski narativ postaje poprište razmene iskustava unutar bića njegovog subjekta i šire zajednice. Naime među govornicima jezika Odia, jednog od indijskih jezika naroda provincije Odiša, autobiografski žanr je tradicionalni način (nacionalnog) samoodržanja u kontekstu života u kolonijalnom i postkolonijalnom svetu (123).

Eber Nena Agugbu Nweze (Ebere Nnenna Agugbue Nweze) "Writing me, Raising Me, Beating the Drums Louder" (Pišem sebe, odgajam sebe, udaram bubnjeve) govori o fiktivnim autobiografijama kao instrumentu žena u Africi i dijaspori da podriju predstavu o ućutkanosti i nevidljivosti žena u društvu i književnosti (137). Ovi narativi čine da žene 
ožive u postkolonijalnom, patrijarhalnom društvu. Da funkcionišu kao predstavnici ili ikone grupe (138).

U okviru eseja "Memory, Trauma, and Resilience: The Autobiographies of Winnie Madikizela Mandela," (Sećanje, trauma i otpor: autobiografija Vini Madikiyala Mandele) Ben Lebdaj (Ben Lebdai) bavi se autobiografskim tekstovima autorke koji su nastali u razmaku od dvadesetosam godina. Autobiografiju i zatvorski dnevnik. Ben Lebdai traga za individualnošću autorke iza ikonične figure ukrštajući naracije o njoj. Da li je harizmatična figura Vini Mandele, njena snaga i sposobnost da govori otvoreno u neprijateljskom svetu proizvod očevog uticaja, sopstvenog društvenog angažmana, prihvaćene ideologije ili jednostavno, ljubavi (61). predstavlja glavnu preokupaciju eseja (61) u kome Lebdaj pokušava da otkrije "ličnu priču u istorijskoj".

Dagmara Drevniak (Dagmara Drewniak) istražuje važnost individualnog iskustva i kolektivnog sećanja u procesu formiranja subjektivnosti. Drevniak analizira dela mađarskih emigranata u Kanadi posle Drugog svetskog rata. U ovim delima Drevniak prati izgradnju sopstvenog identiteta kroz kolektivni i nacionalni identitet. Ispituje granični pojas između autobiografije i memoarskog žanra, utvrđujući da je diskurs personalnog teksta uvek određen politikom i istorijom. Spoj ličnog i društvenoistorijskog neizbežno obeležava pisanje o sebi (94).

U eseju "Memoir as Well as Biography" (Sećanje, kao i biografija), Melani Hejdari (Melanie Heydari) istražuje granični prostor između biografije i autobiografije (280) granični pojas između biografije i autobiografije u delu postkolonijalnog pisca Vikrama Seča (Vikram Seth) Two Lives (Dva života). Seč piše o indijskim imigrantima u Nemačkoj u određenom istorijskom periodu, na početka dvadesetog veka. U kontekstu njihovih životnih priča, Hajdari slika isotorijsku pozornicu tadašnje Nemačke i na njoj predstavlja imigrantsku zajednicu iz Indije. Ovakva slika neizbežno pokreće teme o granicama civilizacija i kultura (280). Tema kolektivnog iskustva imigrantske i kolonijalne istorije i njena sublimacija u književnosti predstavlja osnov za individualno autobiografsko iskustvo autora.

Borba za vidljivost i samopotvrdu kroz pisanje u autobiografijama transrodnih osoba tema je eseja Džona Holija (John C. Hawley). Značaj ovakvih autobiografija je, smatra Holi, označavanje mesta u društvu za 
izražajni prostor pisaca transeksualne orijentacije. Odsustvo empatije društva prema transrodnim osobama Holi opisuje kao marginalizaciju vukući interesantne paralele sa kolonijalnim bićem i njegovim mestom u kolonijalnom društvu. Utemeljivši svoje zaključke u opservacijama Franca Fenona i stavu da je čitava istorija kolonijalizma ispoljena u svakom individualnom crnačkom iskustvu, Holi piše da je čitava istorija neshvatanja, marginalizacije i drugosti transrodnih osoba ispoljena $\mathrm{u}$ individualnom iskustvu i može se čitati kroz narativ koji to iskustvo opisuje.

Pjotr Sobolzik (Piotr Sobolczyk) piše o sagledavanju rodnog identiteta kroz prizmu kulturološkog određenja. U autobiografijama koje problematizuju rodnu tematiku moguće je, stoga, posmatrati koliko kao individualna svedočanstva, tako i kao svedočanstva o ideološkim, istorijskim i kulturološkim osobinama određene zajednice.

Desetak eseja iz zbirke bavi se mogućnostima i granicama žanra autofikcije. Karen Fereira Mejers (Karen Ferreira-Meyers) sagledava žanr autofikcije u kontekstu i prostoru postmodernističke književnosti i ističe poetičke srodnosti autofiktivnog žanra sa šire posmatranom poetikom postmodernizma. Fereire-Mejers ističe da za razliku od klasične biografije autofikcija predstavlja fragmentirano biće subjekta, fiktivno i konstruisano koje u skladu sa opštom perspektivom postmodernizma i posebno poststrukturalizma objašnjava nastanak autofikcije kao novog žanra u širem okrilju personalnog teksta.

Melissa Šuš (Melissa Schuh) istražujući kako se "raskrinkava biće autora" u autobiografijama Gintera Grasa i J.M.Kucija. Šušova svedoči o diskurzivnim efektima izmene prvog i trećeg lica unutar pripovedanja personalnog teksta, dilema koju u svojoj autobiografiji formuliše Ginter Gras kao "izazov da se čovek sakrije pod masku trećeg lica” (287). Šušova analizira interpretativne i izražajne prednosti fiktivne ispovesti kao i dislociranja narativa o sopstvenom životu.

U eseju o autobiografskom tekstu Gertrude Štajn Everybody's Autobiography (Svačija autobiografija), Kristina Savinel (Christine Savinel) ispituje diskurzivne tehnike Štajnove kojima postiže kako reprezentativnost i pripadnost grupi tako i individualnost unutar personalnog teksta. Savinelova postavlja pitanje da li bilo ko može da piše u bilo čije ime, i da li su u tom slučaju biografija i autobiografija zapravo isto (72)? Savinelova govori o pristupu Štajnove pisanju autobiografije u kome sam čin pisanja 
pokušava da ublaži "neizvesnost u pogledu identiteta", a biće se ispoljava kao diskurzivna funkcija, kroz čin govora.

Klod Damaris (Claude Desmarais) preispituje pitanje autentičnosti i "istina" u pisanju o životu stavljajući jedno pored drugog autobiografiju Elijasa Kanetija i njegovu trotomnu biografiju. Ističući veću informativnost biografije u odnosu na autobiografiju. Damaris utvrđuje da autobiografija, izostavljajući važne pojedinosti "ne pripoveda"celu priču”, već izravnava nepravilnosti, okoliši i izbegava "duboke brazde" (88). Biografija zbog ovih objektivnih prednosti poseduje veću sposobnost za stvaranje portreta svog subjekta.

U eseju "From Autobiography to Storytelling: The Works of C.S. Lewis," (Od autobiografije do pripovedanja: dela C. S. Luisa) Daniel Varceha (Daniel Warzecha) piše o irskom piscu C. S. Luisu čije celokupno delo je nadahnuto autobiografskim materijalom. C. S. Lewis piše o detinjstvu i mladosti priznajući uticaje svih stvaralaca iz sveta umetnosti i filozofije kojima se divio i koji su "oblikovali njegovu svest" (104). Unutar svog (auto)fiktivno dela Luis vodi dijalog sa odabranim delima i piscima koji predstavljaju "knjige-matrice među čijim koricama čovek može naći sve ključne ideje, teme i metafore koje će Luis tokom života razvijati u svojoj književnosti" (106).

U eseju "Avoiding Self-Centered Fairytales: Autobiographies by Female Singer-Songwriters," (Izbegavanje egocentričnih bajki: autobiografije kantautorki) Danijela Čana (Daniela Chana) predstavlja na koji način pisac autobiografije može podeliti svoja najintimnija osećanja sa publikom, a istovremeno izbeći neprijatnu privatnost teksta na primeru Tori Amos, kantautorke i književnice. Njeno pisanje o sebi sadrži eseje o temama poput religije, materinstva, rađanja, slave, skitačkog života, ljubavi prema muzici, i mnogih drugih. Izmena pripovedačkog glasa, perspektive i stila, kaoi neprestano prebacivanje pripovedačkog fokusa ne dopušta centralnu ulogu pripovedačkog, a kao rezultat autobiografija je "kompleksna filozofska rasprava u koju je uključeno mnoštvo glasova” (114).

U tekstu "Like Father Like Daughter? (Isti otac) Florin Reviron Pigej (Floriane Reviron-Piegay) predstavlja dva narativa o istoj ličnosti, autobiografiju oca i memoare Virdžinije Vulf istražujući na koji način ideološki markeri utiču na stvaranje slike o sebi i svetu. Naime, patrijarhalni stav Leslija Stivena i moderan, feministički stav Virdžinije Vulf predstavljaju u drugačijem svetlu figuru majke, Julije Stiven. 
Lora Kestor (Laura Castor) govori o mogućnosti uključenja raznih perspektiva u narativ o sopstvenom biću. Razne verzije sopstvenog bića deluju subverzivno u narativu kome autoritet daje jedinstvenost slike o biću. Što je neophodno za bilo kakav pomak u pravcu"samospoznaje i oslobođenja" (239). Kestorova ukazuje na "mnoštvo nivoa samoreprezentacije" (241), odnosno mnogih "senki pod nama" (239). Kestorova polemiše sa Leheunovim stavom (Phillip Lejeune) o postojanju "pakta" između pisca klasične autobiografije i čitaoca kojim se autor obavezuje da govori istinu o sebi (240). Karakteristika žanra autofikcija je isticanje različitosti između pisca teksta i protagonist autobiografije (Gilmore, 2001: 89 cit. u Shands 240), stoga je upravno fikcionalizacija subjekta u žanru autofikcije novootkriveni prostor za njegovo potpunije predstavljanje.

Manuel Brito (Manuel Brito) govori o "eksperimentu kolektivne autobiografije", pisanje autobiografije kao kolektivnog iskustva života zajednice pesnika. Brito piše o projektu kolektivne autobiografije pesničkog kruga u San Francisku koji su svoje individualne umetničke identitete udružili u hibridni književni poduhvat tako su i iskustvo i doživljaj stvarnosti spojili u zajedničku "psihološku avanturu" istraživanja sopstvenog bića u okviru kolektiviteta (270).

Mikolaj Višnjevski (Mikołaj Wiśniewski) jednoj od mogućih uloga fikcionalizovanog sećanja, da "retušira prošlost". U eseju "fiktivnoj autobiografiji Vladimira Nabokova Speak, Memory" Višnjevski piše da u celokupnom opusu Nabokov piše o sebi, stvarajući likove po ugledu na aspekte sopstvene ličnosti, uključujući situacije, iskustva i pojedinosti sećanja, trauma i strahove iz sopstvenog života (307). Retuširanje prošlosti u Nabokovljevom delu ima oblik potrage za "tematskim obrascem" koji od prošlosti čini "razumno delo" (309).

Pamela Rejder (Pamela J. Rader) piše o umetnosti "pisanja života" predstavljajući narativne strategije "prenošenja" avantura života u tekst. Rejderova polazi od najopštijeg pitanja koje se postavlja pri pisanju/čitanju memoarske literature, da li je iza tekstualne kontrukcije autentično biće autora? Da li je forma ispovesti u stanju da predstavi istinu o biću ili stvara novu (ne)atutentičnu, fiktivnu konstrukciju. Protagonista, piše Rejderova, koristi postojeće narativne trope koji nužno oblikuju njegov iskaz i samim tim ga menjaju (315). Da li je u tom slučaju možemo smatrati da je slika bića koja nastaje u tekstu autentična predstava stvarnog bića? 
O žanrovskim razgraničenjima autofiktivnog teksta i srodnih ili graničnih narativa govori Šona Kazar (Seana Kozar) govori o srodnostima u pristupu između dva naizgled poetički veoma različita žanra, autobiografije i narodne priče. Tematska sličnost je u momentu ispovesti, govoru o sazrevanju, životnom putu i ključnim arhetipskim momentima na tom putu. Najveća sličnost je u očekivanju publike i uverenju u da je priča "istinita" (346). Ispovedna forma kako u autobiografiji, tako i u foklornoj priči stavlja junaka u centar zbivanja, a rekonstruisana prošlost ima oblik sećanja koje je oblikovalo junaka koji je pred nama.

Najzad, nekoliko eseja bavi se pisanjem autobiografije kao funkcionalnog teksta. Nekoliko eseja bavi se terapeutskom ulogom pisanja o sebi. Prvi od njih govori o ulozi "autobiografske fikcije u tumačenju sopstvene ličnosti” (51). Belinda Hilton (Belinda Hilton) ističe da autofikcija stvara prostor za istraživanje razloga zbog kojih imamo izvesna osećanja ili reagujemo na određeni način. Osećanja izbijaju iz naših sopstvenih naracija o sebi, smatra Hiltonova i potrebno ih je otkriti i preispitati (56).

Lora de Nervo-Gevoti (Laure de Nervaux-Gavoty) analizira specifičnu perspektivu u pisanju autobiografije koju stvara bolest: traumatično iskustvo bolesti i lečenja, Gubitak pređašnjeg identiteta i izgradnja novog u odnosu na izmenjeno telo i svest. Pisanje predstavlja terapiju kroz proces stvaranja novog identiteta. Nervo-Gavoti ističe promenu perspektive u odnosu na klasične autobiografije u kojoj je evidentna superiornost svesti u odnosu na telo. U situaciji u kojoj postoji izmenjena perspektiva na osnovu telesne (traumatične) promene, telo se nameće kao superiorno u porcesu stvaranja budućeg identiteta (258).

U eseju o pisanju autobiografije kao terapiji Tanja Rajfenret (Tanja Reiffenrath) govori o preispitivanju kulturološkog shvatanja bolesti i terapije kroz životopise o njoj. Rajnferetova govori o tekstovima koji su sve zastupljeniji u drugoj polovini dvadesetog veka pokušaj razumevanja sopstvenog bića kroz optiku terapije i nade u izlečenje. Ove autobiografije karakteriše senzibilnost, nesigurnost i pokušaj izoštravanja percepcije (359). Za razliku od klasičnih autobiografija pisaca koji su preživeli trauma bolesti, autofiktivni tekstovi ne odnose se prema bolesti kao prema "prekidu" uobičajene životne rutine, već preispituju novo životno iskustvo i iskustvo sagledavanja stvarnosti kroz novu optiku.

Tvrdnja Kerstin Šends da "moramo neprestano i uvek iznova tumačiti naše živote i svet u kome živimo, a to možemo samo uz pomoć 
priča i u okviru diskursa" (Shands, 2005: 183), ističe fikcionalizaciju kao jedno od glavnih obeležja autofiktivnog teksta. Intrepretacija "avantura" i reinterpretacija iskustva podleže neizbežno ograničenjima narativnih strategija i diskurzivnih mogućnosti. Stoga, da bi proširio horizonte, personalni tekst zalazi u druge žanrovske, poetičke i stilske prostore. Izgleda da su mogućnosti transformacije nesagledive, kao i okviri ovog žanra. Ključ tumačenja autofiktivnog teksta, međutim, ostaje da pruži odgovor na (naizgled) jednostavno pitanje, "u čemu je značaj prenošenja [ovog ] života u tekst" (7)?

\section{Literatura:}

Cohen, Phil (2013). Reading Room Only: Memoir of a Radical Bibliophile. Nottingham: Five Leaves.

Doubrovsky, Serge, (1977). Fils, Paris : Galilée.

Gilmore, Leigh (2001). The Limits of Autobiography: Trauma and Testimony. Ithaca: Cornell UP.

Hindmarsh, D. Bruce (2005). The Evangelical Conversion Narrative: Spiritual Autobiography in Early Modern England. Oxford: Oxford UP.

Ochs, Elinor and Lisa Capps. (1966). "Narrating the Self." Annual Review of Anthropology, Vol. 25, 19-43.

Shands, Kerstin W., Mikrut, Giulia Grillo, Pattanaik, Dipti R/, and Ferreira-Meyers, Karen, (eds.) (2015). Writing the Self: Essays on Autobiography and Autofiction. Stockholm: Södertörns högskola.

Smith, Sidonie, and Julia Watson (2010). Reading Autobiography: A Guide for Interpreting Life Narratives. Minneapolis: U of Minnesota P. 
Aleksandra V. Jovanović

\section{Summary}

\section{WRITING ABOUT ME, WRITING ME}

This essay attributes to the ongoing discussion about the distinction of autofiction and classical autobiography. The term autofiction was coined in 1977 by the French novelist Serge Dubrovsky who so attempted to define his own literary style. This started the discussion among critics about the genre's conventions and narrative startegies. The collection Writing the Self features thirty essays which explore the genre of autofiction in the broader context of the personal narrative. Questions about the onthological status of the personal narrative and the author/ protagonist distinction are in these essays analyzed within the more general theoretical focus on postmodernism, postcolonialism and gender. The authors of the essays also look for the cultural, political and historical markers within the personal text. The aim of this article is to show the main concerns which are discussed in the essays of the present collection and to draw attention to most frequent issues of the current theoretical practice in this field.

Key words: autobiography, autofiction, author, personal text, authenticity, history, ideology, culture, writing. 